\title{
Esthetic neck dissection using an endoscope via retroauricular incision: a report of two cases
}

\author{
Jae-Young Kim ${ }^{1}$, Hoon $\mathrm{Cho}^{1}$, In-Ho Cha ${ }^{1,2}$, Woong Nam ${ }^{1,2}$ \\ ${ }^{1}$ Department of Oral and Maxillofacial Surgery, ${ }^{2}$ Oral Cancer Research Institute, College of Dentistry, Yonsei University, Seoul, Korea
}

\begin{abstract}
J Korean Assoc Oral Maxillofac Surg 2014;40:27-31)
Various surgical techniques, such as endoscopic surgery and robotic surgery, are developed to optimize the esthetic outcome even in operations for malignancy. A modified face-lift or retroauricular approach are used to minimize postoperative scarring. Recently, robot-assisted surgery is being done in various fields and considered as favorable treatment method by many surgeons. However its high cost is a nonnegligible fraction for many patients. On the other hand, endoscopic surgery, which is cheaper than robotic surgery, is minimally invasive with contentable neck dissection. Although it is a difficult technique for a beginner surgeon due to its limited operation view, we suppose it as an alternative method for robotic surgery. Herein, we report two cases of endoscopic neck dissection via retroauricular incision with a discussion regarding the pros and cons of endoscopic neck dissection.
\end{abstract}

Key words: Endoscopes, Neck dissection, Head and neck cancer

[paper submitted 2013. 12. 30 / revised 2014. 2. 7 / accepted 2014. 2. 10]

\section{Introduction}

Various surgical techniques have been developed to optimize esthetic outcomes even in operations for malignancy. Unlike other parts of the body, postoperative scars are especially noticeable in the head and neck area. Thus, it is crucial to minimize postoperative scarring in these areas, especially in neck dissection (ND). Robot-assisted and endoscopicassisted surgeries are typical examples. Kang et al. ${ }^{1}$ first reported robot-assisted modified radical ND in 2010. They performed the operation via a transaxillary approach, but difficulties in approach to level I, an important area for oral cavity cancer treatment, were encountered ${ }^{2}$. To overcome this limitation, ND via modified face-lift or the retroauricular ap-

\footnotetext{
Woong Nam

Department of Oral and Maxillofacial Surgery, College of Dentistry, Yonsei

University, 50, Yonsei-ro, Seodaemun-gu, Seoul 120-752, Korea

TEL: +82-2-2228-2971 FAX: +82-2-2227-8022

E-mail:omsnam@yuhs.ac
}

(C) This is an open-access article distributed under the terms of the Creative Commons Attribution Non-Commercial License (http://creativecommons.org/licenses/by-nc/3.0/), which permits unrestricted non-commercial use, distribution, and reproduction in any medium, provided the original work is properly cited.

Copyright (C) 2014 The Korean Association of Oral and Maxillofacial Surgeons. All rights reserved. proach using robotic surgery was attempted by the same author. Robot-assisted ND has many advantages, such as excellent esthetic outcomes and good visualization during surgery, but its high cost is a problem for most patients. Endoscopicassisted surgery can be an alternative and more cost-effective option compared to robot surgery, as Byeon et al. ${ }^{3}$ Recently, we treated two patients who underwent endoscopic-assisted ND via a retroauricular approach and had excellent esthetic outcomes. Herein, we report these cases and discuss the pros and cons of endoscopic ND.

\section{Cases Report}

\section{Case 1}

A 63-year-old male patient visited the Department of Oral and Maxillofacial Surgery at Dental Hospital of Yonsei University of College of Dentistry in Korea. His chief complaint was an unhealed oral ulceration which appeared 8 months prior. Incisional biopsy had been performed by another hospital, which revealed invasive squamous cell carcinoma. The patient also had hypertension, for which he was receiving medication. He smoked two cigarettes a day for more than 30

This work was supported by the Priority Research Centers Program through the National Research Foundation of Korea (NRF) funded by the Ministry of Education, Science and Technology (2009-0094027). 
years. The ulcerative lesion was present on the lingual side of \#36, \#37 and was $3.0 \times 2.0 \mathrm{~cm}$ in size. The lesion had an irregular margin without bleeding tendency. Additional diagnostic imaging, including magnetic resonance imaging (MRI) and positron-emission tomography (PET), were performed to determine extent of surgery. There was no mandibular or metastatic lymph node invasion, nor were there metastatic lesions on any other organs (cT2N0M0, stage II). Thus, wide excision with marginal mandibulectomy, selective neck dissection (SND) (I-III) via endoscope, and repair of the soft tissue defect with Megaderm (L\&C Bio, Seongnam, Korea) were performed.

It took almost 5 hours to complete endoscope-assisted SND (I-III), with $450 \mathrm{cc}$ of blood loss during the operation. The final diagnosis confirmed the initial clinical staging (pT2N0M0, stage II). There was mild marginal mandibular branch weakness, which might also have arisen in conventional ND. The patient was discharged 13 days after surgery without any other complications.

\section{Case 2}

A 56-year-old male was referred from a local clinic for evaluation of a tongue mass. It appeared 3 months prior and gradually increased in size. It was erosive and ulcerative with induration and bleeding tendency. He had no specific medical history. The patient had smoked 10 cigarettes a day for 15 years. An incisional biopsy was performed and confirmed a diagnosis of invasive squamous cell carcinoma. MRI and PET demonstrated no regional or distant metastasis (cT2N0M0, stage II). Consequently, wide excision with endoscopic ND, reconstruction of the surgical defect with a radial forearm free flap, and repair of the resulting forearm defect with Megaderm were performed.

It took almost 3.5 hours to complete endoscope-assisted SND (I-III), with $200 \mathrm{cc}$ of blood loss during the operation. The final diagnosis confirmed the clinical staging (pT2N0M0, stage II). Unlike in case 1 , no postoperative facial nerve weakness was observed. The patient was discharged 16 days after surgery without any complications.

\section{Surgical procedure}

Surgery was performed as described in a previous report ${ }^{3}$. Under general anesthesia, the patient was placed in the supine position. Incision line and anatomical landmarks for endoscpoic neck dissection were outlined on patient's neck.(Fig.

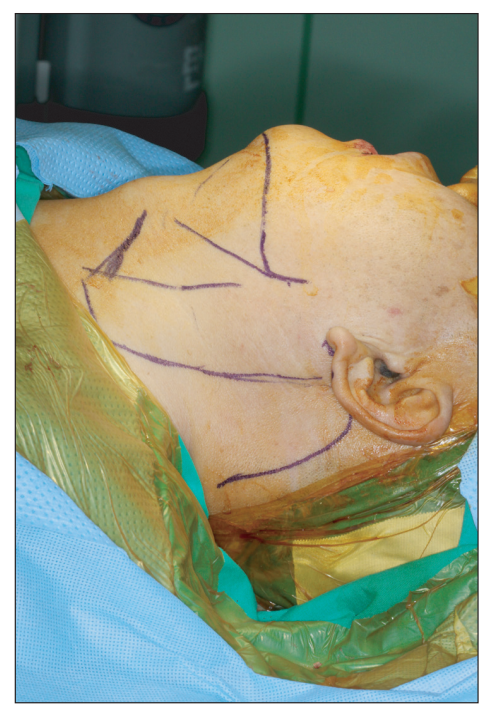

Fig. 1. Patient position and design for retroauricular approach. Patient laid supine position with neck extension. Outline of sternocleidomastoid muscle, omohyoid muscle, inferior border of mandible, and incision line were identified.

Jae-Young Kim et al: Esthetic neck dissection using an endoscope via retroauricular incision: a report of two cases. J Korean Assoc Oral Maxillofac Surg 2014

1) A retroauricualr incision was used to approach the sternocleidomastoid muscle (SCM) and a skin flap was created. The SCM muscle was exposed, then we continued subplastysmal dissection inferiorly and anteriorly until we reach the omohyoid muscle, hyoid bone and the midline of the neck. During skin flap elevation, a self-retaining retractor (Sejong Medical Corporation, Paju; Sangdosa, Seoul, Korea) was used for good visualization of the surgical field. A nerve stimulator was used to identify the marginal mandibular branch of the facial nerve. We began ND with sufficient skin flap elevation. Level IIb was dissected under direct visualization with anterior retraction of the SCM muscle. Some portions of level Ib, IIa, and III were also dissected under direct visualization. Then, a 30-degree endoscope $(10 \mathrm{~mm}$ in diameter, $30 \mathrm{~cm}$ in length; Stryker, San Jose, CA, USA) was applied in the level I area followed by fixation with an endoscope holder (Karl Storz, Tuttlingen, Germany).(Figs. 2, 3)

Dissection of the anterior belly area (level Ia) was performed; then, level Ib, which contains the submandibular gland, was dissected. Harmonic curved shears (Harmonic Ace 36P; Johnson \& Johnson Medical, Cincinnati, OH, USA) were used to cauterize minor vessels and dissect tissues. The distal facial artery and vein were ligated with premium surgiclips (Covidien, Dublin, Ireland); the submandibular ganglion, Wharton's duct, proximal facial artery and vein were cut after ligation with surgiclips. The lingual artery and hypoglossal nerve were preserved. We demarcated the level of 


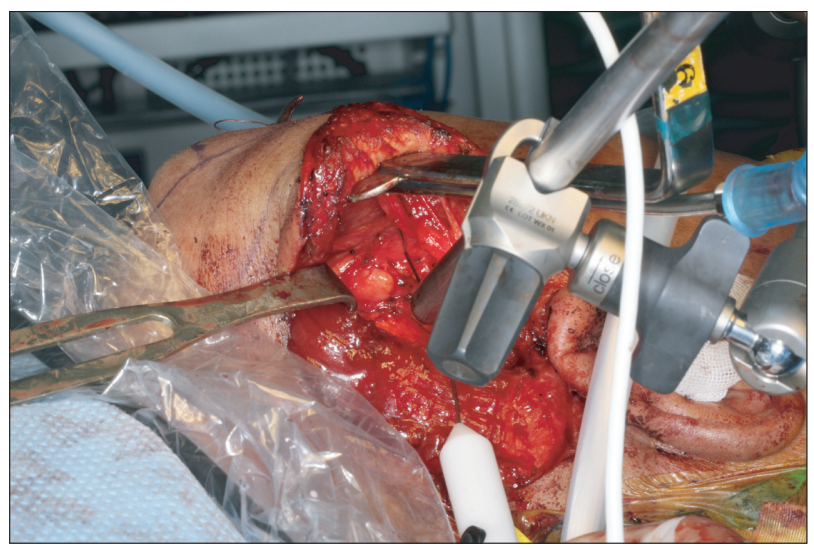

Fig. 2. Preparation for endoscopic neck dissection. Self-retaining retractor was fixed and endoscope was being inserted into level lb area.

Jae-Young Kim et al: Esthetic neck dissection using an endoscope via retroauricular incision: a report of two cases. J Korean Assoc Oral Maxillofac Surg 2014

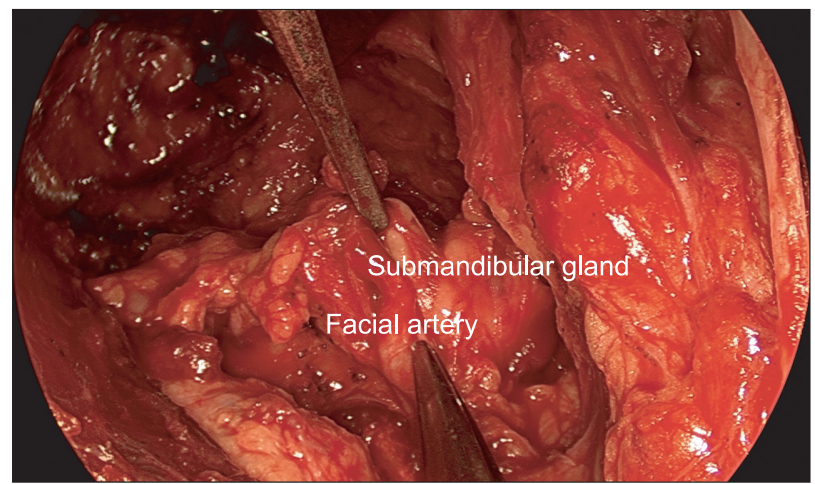

Fig. 3. Dissection on level lb area (endoscopic view). Submandibular gland and facial artery were identified.

Jae-Young Kim et al: Esthetic neck dissection using an endoscope via retroauricular incision: a report of two cases. J Korean Assoc Oral Maxillofac Surg 2014

omohyoid muscle, which is inferior to the border of level III, and dissected lymphoadipose tissue superiorly from inferior margin using endoscope. Finally, dissection of the carotid artery and internal jugular vein was performed with posterior retraction of the SCM. It was possible to perform the final step under direct visualization. No remarkable bleeding or damage to important anatomical structures was observed.

Micro-vascular surgery was performed in case 2 as usual manuals which have been done in conventional neck dissection.(Fig. 4) Donor vessels such as the proximal portion of facial artery, superior thyroid artery, and related veins were observed well under microscope. No additional device was needed. However, an assistant had to retract the skin flap with an Army-Navy retractor for visualization of the operative field.

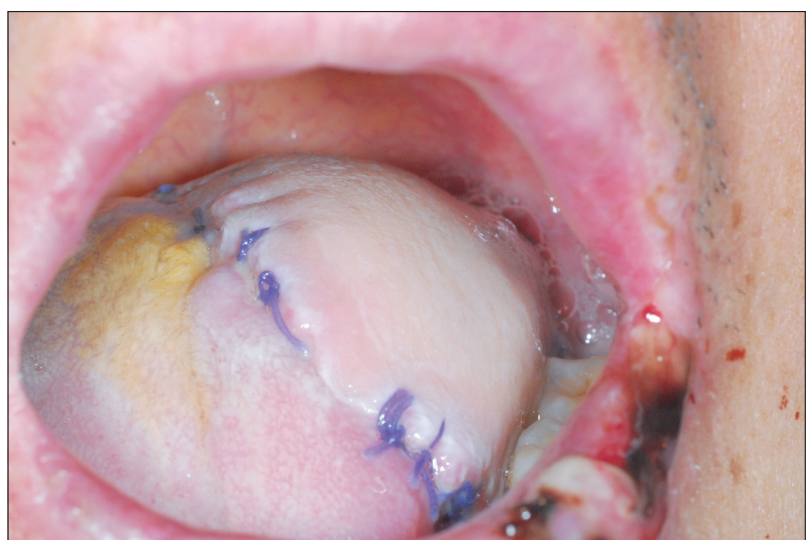

Fig. 4. Reconstructed tongue with radial forearm free flap (Case 2, postoperative day 17). Transplanted radial forearm free flap was survived successfully. Micro-anastomosis was performed via retroauricular approach. The color and texture was favorable.

Jae-Young Kim et al: Esthetic neck dissection using an endoscope via retroauricular incision: a report of two cases. J Korean Assoc Oral Maxillofac Surg 2014

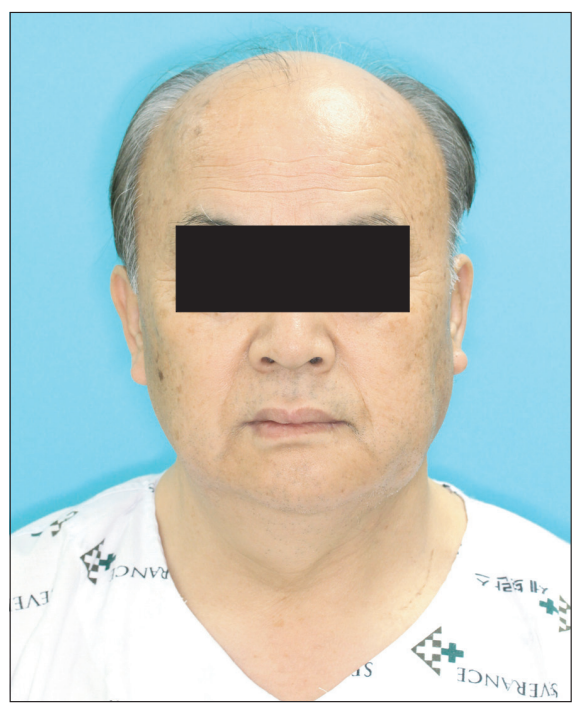

Fig. 5. Clinical photograph (Case 1, frontal view, postoperative day 12). Postoperative scar is not identified at frontal photograph. Surgeons might achieve esthetic result after neck dissection. Jae-Young Kim et al: Esthetic neck dissection using an endoscope via retroauricular incision: a report of two cases. J Korean Assoc Oral Maxillofac Surg 2014

\section{Discussion}

Gagner ${ }^{4}$ introduced endoscopic surgery as an alternative to conventional open neck surgery for parathyroidectomy in 1996. Since then, various trials for endoscopic surgery on the neck, including thyroidectomy ${ }^{5}$, submandibular gland excision $^{6}$, sentinel node biopsy ${ }^{7}$, and $\mathrm{ND}^{3}$, have been performed. This technique was developed gradually and is currently used in the treatment of many patients.

There are some advantages to endoscopic surgery com- 


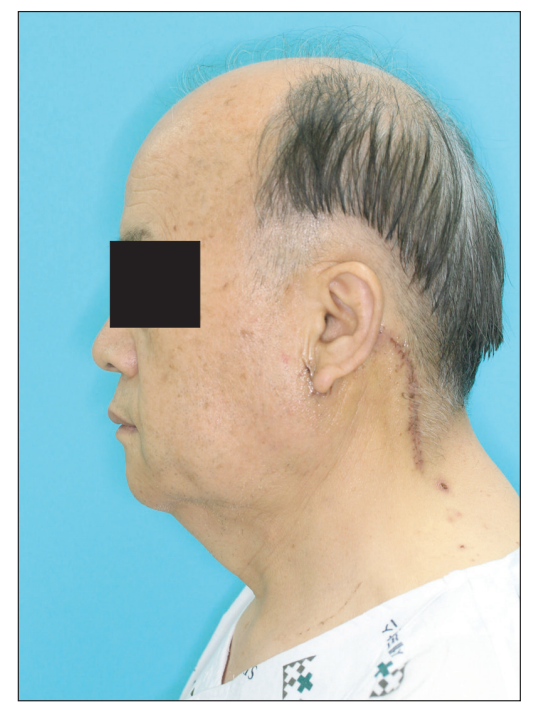

Fig. 6. Clinical photograph (Case 1, lateral view, postoperative day 12). Postoperative scar can be hidden in hairline. Jae-Young Kim et al: Esthetic neck dissection using an endoscope via retroauricular incision: a report of two cases. J Korean Assoc Oral Maxillofac Surg 2014

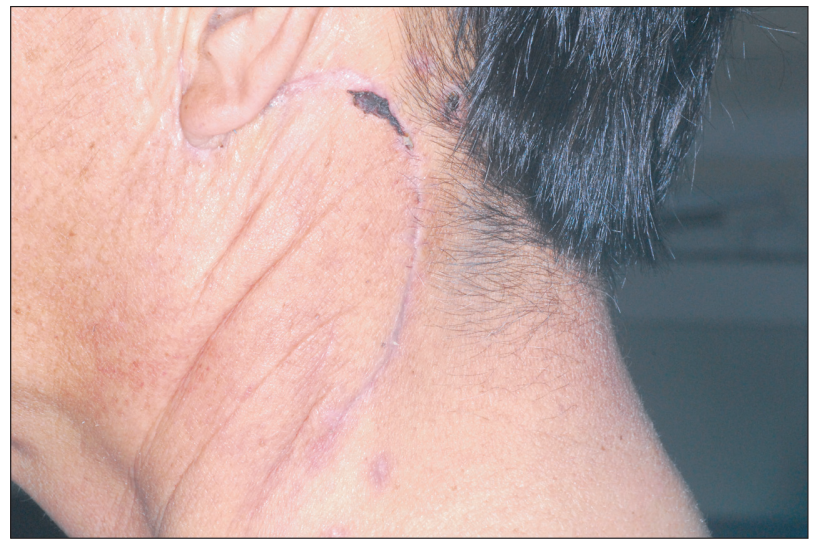

Fig. 7. Clinical photograph (Case 2, lateral view, postoperative day 17). The scar is relatively short compared with conventional methods and can also be hidden in hairline.

Jae-Young Kim et al: Esthetic neck dissection using an endoscope via retroauricular incision: a report of two cases. J Korean Assoc Oral Maxillofac Surg 2014

pared to conventional methods. First of all, optimized esthetic outcomes are possible. Although postoperative period is not enough to discuss about results of postoperative scar, it cannot be seen easily in the frontal view because the incision line is hidden along the posterior neck.(Figs. 5-7) Second, the procedure is minimally invasive and patients typically recover faster. The incision line is also shorter than that of the conventional method. Although more retraction of the skin flap is needed and causes stretching of the flap, this did not lead to any postoperative complications in the present cases. Patients experienced less swelling and more rapid healing. We found that accurate ND could be obtained by the endoscopic approach. In the conventional method, it is difficult to dissect level IIb precisely, but the endoscopic approach provides the best field of view on level II and favorable fields of view on levels $\mathrm{Ib}$ and III.

However, this technique may not be appropriate for unskilled operators who have less experience with endoscopy or are unfamiliar with surgical anatomy. Endoscopy provides limited direct visualization compared to the conventional method, so it can be difficult to recognize the exact area where is being operated and control unexpected hemorrhages. We should be especially careful when dissecting level Ia for two reasons. First, the overlying skin tends to be thin and punctured easily, since there is no platysma muscle on level Ia. Second, it is difficult to dissect the lymphoadipose tissues on level Ia precisely compared with the conventional method because of the limited surgical field. This technique may also not be appropriate for lesions on the floor of the mouth, near the midline, or along the anterior mandible where lymphatic drainage occurs to level Ia.

Byeon et al. ${ }^{3}$ reported the advantages of robotic surgery compared with endoscopic surgery. First, they proposed that endoscopic surgery causes inconveniences to the operator and assistant due to limited space. Second, the robotic system has wrist articulated movement, which enables an unlimited operation field in a narrow working space compared to the endoscope. Third, the robotic system provides more assistance with its arm. However, its high cost is a distinct disadvantage of robotic surgery ${ }^{3,8}$. According to our experience, most patients diagnosed with oral cavity cancer are elderly, and are more concerned about cost than neck scarring.

Prominent postoperative scarring can be a major problem for patients. Robotic surgery provides minimal postoperative scarring, but is very expensive. Endoscopic ND is a little bit more expensive than the conventional approach, but cheaper than robotic surgery, and causes fewer scars compared to the conventional approach. Thus, we consider endoscopic ND as an alternative to robotic surgery in terms of cost and postoperative scarring. Oral and maxillofacial surgeons should make an effort to gain experience in endoscopic surgery and robotic surgery.

Unfortunately, there is no long-term follow-up information on patient outcomes involving these surgeries. Thus, it is impossible to compare oncologic outcomes between endoscopic ND and conventional ND. Further studies are required to gather more data on endoscopic ND.

\section{Conflict of Interest}

No potential conflict of interest relevant to this article was 
reported.

\section{References}

1. Kang SW, Lee SH, Ryu HR, Lee KY, Jeong JJ, Nam KH, et al. Initial experience with robot-assisted modified radical neck dissection for the management of thyroid carcinoma with lateral neck node metastasis. Surgery 2010;148:1214-21.

2. Lee HS, Kim WS, Hong HJ, Ban MJ, Lee D, Koh YW, et al. Robot-assisted Supraomohyoid neck dissection via a modified face-lift or retroauricular approach in early-stage $\mathrm{cN} 0$ squamous cell carcinoma of the oral cavity: a comparative study with conventional technique. Ann Surg Oncol 2012;19:3871-8.

3. Byeon HK, Holsinger FC, Koh YW, Ban MJ, Ha JG, Park JJ, et al. Endoscopic supraomohyoid neck dissection via a retroauricular or modified facelift approach: Preliminary results. Head Neck
2014;36:425-30.

4. Gagner M. Endoscopic subtotal parathyroidectomy in patients with primary hyperparathyroidism. Br J Surg 1996;83:875.

5. Miccoli P, Berti P, Bendinelli C, Conte M, Fasolini F, Martino E. Minimally invasive video-assisted surgery of the thyroid: a preliminary report. Langenbecks Arch Surg 2000;385:261-4.

6. Baek CH, Jeong HS. Endoscope-assisted submandibular sialadenectomy: a new minimally invasive approach to the submandibular gland. Am J Otolaryngol 2006;27:306-9.

7. Werner JA, Sapundzhiev NR, Teymoortash A, Dünne AA, Behr T, Folz BJ. Endoscopic sentinel lymphadenectomy as a new diagnostic approach in the N0 neck. Eur Arch Otorhinolaryngol 2004;261:463-8.

8. Tae K, Ji YB, Song CM, Jeong JH, Cho SH, Lee SH. Robotic selective neck dissection by a postauricular facelift approach: comparison with conventional neck dissection. Otolaryngol Head Neck Surg 2013. [Epub ahead of print] 